\title{
Public anxiety, trust, and the role of mediators in communicating risk of exposure to low dose radiation after the Fukushima Daiichi Nuclear Plant explosion
}

\author{
Saho Tateno and Hiromi M. Yokoyama
}

\begin{abstract}
The explosion at the Fukushima Nuclear Plant highlighted serious social concerns about risk communications; the public found it difficult to take preventive actions based on scientific information of radioactive fallout. We investigated public perception of the risks from low dose radiation and the role of information providers through the Internet survey focusing on parents in four Japanese regional groups. Mothers felt more anxious than fathers in Fukushima but not in further groups, and that the furthest group felt the most ambiguous anxiety. Their anxiety derived from distrust of the government and uncertainty about scientific information, rather than the lack of knowledge although risk communication emphasized learning the scientific mechanism. The mediators should provide more information for individual decision-making of day-to-day risk management in regions with different levels of radiological contamination; key issues include improving parents' perceived control to their lives and easing their tension of responsibility to children's health.
\end{abstract}

\section{Context}

Fukushima as the third case of nuclear disaster

Fukushima nuclear disaster was a practice scenario for risk communications. The explosion at the Fukushima Daiichi Nuclear Plant triggered by the tsunami of the Great East Japan Earthquake on March 11, 2011, had an enormous impact on Japanese society. It raised many issues regarding suitable procedures for managing the risk of radioactive fallout and disseminating scientific information.

Since the early 2000s and before the nuclear crisis, the government had frequently used the phrase "pursuing the safe and secure society." In April 2004, the report summarizing the findings of a "meeting on how to construct the safe and relievable society with science policy" was published, which led the Ministry of Education, Culture, Sports, Science and Technology-Japan (MEXT) to establish "the Office of Science and Technology for a Safe and Secure Society, Policy Division, Science and Policy Bureau" in 2005. Although the program represented an effort to improve the government's communications initiative regarding risk management and safety issues 
associated with science and technology, challenges in smooth interactions between the public, experts, and mediators were evident for the crisis that followed the Fukushima nuclear disaster. Consequently, efforts to protect the public from radioactive hazards were not effective as desired.

There have been a lot of controversies regarding communication after the disaster especially about the way of providing risk information. One of them was the government's (i.e., MEXT's) delayed timing for the release of information from SPEEDI (System for Prediction of Environmental Emergency Dose Information). ${ }^{2}$ More residents living near the plant in the Fukushima prefecture could have been alerted to evacuate much earlier with the system, however, the government announced, "The radioactive fallout does not have any immediate health effects," making the public doubt the government's reassurances., ${ }^{3,4}$

Another example of controversy and information confusion concerned the actions of academic societies; the Meteorological Society of Japan made its members refrain from personally publishing prediction data about radioactive fallout spread from the plant. ${ }^{5}$ Even with full media coverage of the disaster and subsequent publications of books about radiation for risk communication, the public did not trust the government, experts, or the media, and therefore, there was considerable anxiety about low dose radiation from the environment and food intake. ${ }^{6}$

The health effects of low dose radiation have been uncertain, according to several international organizations. For example, the International Commission on Radiological Protection (ICRP) published a report recommending that humans control annual individual exposure to radiation to 1 millisievert per year. Local governmental agencies, such as Fukushima's prefectural office, have worked to remove radioactive fallout from the land and improve risk communications by organizing forums. ${ }^{7}$ In April 2012, the government set up a system for monitoring food markets and allowing public access to the resulting data, ${ }^{8}$ but the anxiety remains.

In a survey conducted in March 2011 by a think tank ("nri"), 80\% of respondents selected NHK (Japan Broadcasting Corporation) as the most credible information source, and $29 \%$ of respondents believed that the government lost credibility after the disaster. ${ }^{9}$ It appears, therefore, that the extent of public trust toward information providers such as journalism, the government and experts changed after the disaster because of attitudes about releasing information. In this article, by reviewing the relevant literature in the past and looking at our data from the case of Fukushima nuclear accident, we would like to develop the further discussion of risk communication associated with low dose radiation after a nuclear accident, especially focusing on how to deal with public anxiety and distrust of information providers.

\section{Risk perception research after nuclear accidents}

Once a nuclear accident occurs, the society confronts the risks of radiation and it has to consider risk management according to the studies conducted after Three Mile Island accident in 1979 and Chernobyl accident in 1986. Earle and Cvetkovich discussed, as lessons from Chernobyl, that radioactive hazards can be managed in three general 
ways: "(a) through improved engineering and technology; (b) through regulation; (c) through communication" (p173). ${ }^{10}$ For better communication, the third one, public perception of radiation has been studied every time after the nuclear accidents.

Studies of the perception of risk from radiation by Weart and Slovic described that public people tend to have special sensitivity to the radiation exposure: they see more risks of radiation technology than most of technical experts see. ${ }^{11,12}$ Slovic also added that, overall, public perception of radiation technology differs in accordance with how the technology is used, for instance, as medical treatment, as power generation or as weapon. ${ }^{12}$ The studies of public perception after the nuclear accidents have developed after the cases of Three Mile Island and Chernobyl.

Perception research after Three Mile Island focused on an expectation of control in the lives after the accident. Langer thinks that maintaining an expectation of control is essential to develop each one's sense of wellbeing as people affected by a disaster feel lack of control in their lives after the incident. ${ }^{13}$ The individual levels of perceived control related to the decision-making on whether each one moved out of the local affected area near the damaged nuclear plant or not, as the result by Prince-Embury and Rooney showed, and a tendency of such migration could be predictable primarily by demographic variables like age and years of resident near the plant rather than individual attitude to the accident. ${ }^{14,15}$ They also described that the lack of perceived control led the public to move out and to distrust of experts who explained the risks of radiation even though the levels of worry between who moved and who stayed were similar. $^{15}$

In addition to the perceived control, another issue of deficiency after Three Mile Accident was that the lack of the information of the risks about the accident increased the level of public anxiety. Research by Prince-Embury and Rooney presented that the local people who moved after the accident and were not parents of children under the age of 18 showed more psychological symptoms such as depression, increased worry, loss of faith in experts and less perceived control about their lives than those who had not moved; the report concluded that the results derived from the lack of the information. ${ }^{15}$ Baum, Gatchel, and Schaeffer discussed that the lack of information about the exact amount of radiation released during Three Mile Island accident, maximal levels of radiation allowable for human safety, and the possibility of another accident made the residents think living in more uncertainty without control and feel more stress. ${ }^{16}$

In the perception research by Eiser et al. after Chernobyl accident, farmers and parents in the closest region to the plant felt the strongest psychological reaction, and the research pointed out that it was due to the issues of food contamination; farmers prepare it for their consumers and parents prepare it for their children. ${ }^{17}$ In conclusion, one's responsibility or fear to the lack of responsibility for the lives of others was a key issue of risk perception then. After the Chernobyl accident, Hoijer noted that men and women focus on and absorb different aspects of available information about radiation. ${ }^{18}$ There would be difference in risk perception between fathers and mothers.

Compared to Three Mile Island accident, more information related to the accident was provided to the public in the case of Chernobyl. However, the way of providing the 
information of radiological risks became a more critical issue. To demonstrate the situation, an article referred to the Chernobyl disaster as an information disaster, and it described the public's efforts in West Germany to seek the most credible information sources. It was concluded that "expertise" and "trustworthiness" were indispensable elements when judging the credibility of these sources. "During the weeks and months following the accident many people were unsure about what health consequences to expect for their children and themselves, and about what precautions to take. A lack of clarity and contradictions in the information published let critics speak of an information disaster."19 The kind of the information was very important as Renn presented; when threatened by a hazard, the public has little need for technical detail; what is needed is the information of how to cope, not information about the hazard but information about hazard management. ${ }^{20}$

The third case of a nuclear disaster in the world was Fukushima nuclear plant explosion. Japan has been through some cases of risk communication associated with radiation including the case in Hiroshima and Nagasaki. Hippel touched on a topic of psychological consequences in terms of Fukushima accident in his article by comparing to the case of Chernobyl reported by Chernobyl Forum: in Chernobyl, the exposed population had twice level of anxiety and 3-4 times more with poor subjective health situation than controls. ${ }^{21,22}$ He expected that a similar tendency would be shown in the case of Fukushima. The public perception research in the case of Fukushima should be necessary to investigate the exact psychological situation of the exposed residents near the plant.

\section{Risk communication and public perception}

According to Lemyre, main issues of mass decontamination events like a nuclear accident are categorized into: 1) perception, 2) somatization, 3) media role and communication, 4) information sharing, 5) behavioral guidance and 6) organizational issues. ${ }^{23}$ These elements make the social dynamics to a nuclear accident, and there are many researches on the correlation among them. Now, we discuss more about risk communication itself.

Leiss presented how the practice of risk communication has been developed: The term risk communication first appeared in the literature in $1984 .{ }^{24}$ The basic idea in the 1980 s and early 1990s was that understanding public risk perception would enable researchers to develop risk communication models and experiments, and to design more effective risk communication, which could be used by practitioners in their everyday work. Boholm described numerous types of activities in environmental risk communication: stimulating interest in environmental health issues, increasing public knowledge, influencing attitudes and behaviors of people, acting in situations of emergency or crises, aiding in decision making, and assisting in conflict resolution. ${ }^{25}$ Every risk situation requires different communication, and Renn points out the importance of adjusting risk communication to the specific needs of the people so that they can make a decision of their risk situation in accordance with how much they are prepared and what extent of measures of safety they have. ${ }^{20}$ 


\section{Risk communication and trust}

Trettin and Musham categorized three parties during the process of risk communication as follows: individuals, groups, or organizations. ${ }^{26}$ Social standpoints of people such the public, the media and the experts as well as the government communicate one another. Mogan et al insisted that one of the keys to risk communication is supplying the public with the "information they need to make informed, independent judgments about risks to health, safety and the environment" (p4). ${ }^{27}$ There are also several key determinants in risk perception of the public in risk communication which were discussed in previous literatures such as trust, affect and emotions as Sjoberg and Visshchers. ${ }^{28,29}$ In social psychology field, it is indicated that the less trusted an organization is, the stronger the anxiety level of citizens regarding hazardous situations involving the organization. ${ }^{30}$ Research by Holt and another survey by Dohrenwend, Dohrenwend, Kasl, \& Wowheit, documented a higher level of distrust of authorities after Three Mile Island accident, and how the audience perceived the information in risk communication after the nuclear accident strongly related to the faith in experts. ${ }^{31,32}$

There have been a number of articles on how to build public trust to information providers on the matter of science and technology. An article introduced the case of Cumbrian sheep farmers in the United Kingdom who responded to scientific advice concerning radioactive fallout because of Chernobyl, and it suggested that experts' attitudes toward society should become more reflexive, as much as the public people are, questioning the "deficit model": a one-way enlightening or educating communication style to explaining technical knowledge. ${ }^{33}$ A two-way communication would build more trust between experts and the public; otherwise, the information catastrophe would be attributed to ideological disorganization within the social clusters of information providers as shown in another article described the effects of Chernobyl in Norway as the endangerment of culture and health together. ${ }^{34}$

A recent article argued that for the development of public trust, policy makers and experts should respect each other; additionally, mediation should play a more prominent role with participation by NGOs, news services, and online portals throughout the world. ${ }^{35}$ Another suggestion was the construction of a system to support better communication between experts and members of society to facilitate evidencebased policy making. ${ }^{35}$

\section{Risk communication and the media}

Again, the media play the important role in risk communication after a nuclear accident, and there some researches focused on it. For example, Lemyre et al insisted that, "Public perceptions are influenced not only be the degree of exposure to a hazard, but also by the content and delivery of risk messages" (p20). ${ }^{23}$ Mazur and Lee also discussed that it is not the content that influences people's opinions, but the sheer amount of coverage. Other researches suggested that, in Durfee's work, a tone of reporting influence the public perception of risk (a tone of changing society is more influential than that of status quo or balanced news), and, in Wahlberg's work, the 
media has influenced on public perception of risk, especially general risk perception rather than personal risk perception. ${ }^{37,38}$

\section{Studies of reporting three nuclear disasters}

How the media deal with the emotions of the audiences is another key issue for communicating risks of low dose radiation. Regarding news features of the Chernobyl accident, research showed that some journalists and TV news anchors in the United States relied on headlines that induced fear. The article pointed out that U.S. news reports of Chernobyl compared it to the Three Mile Island accident, thus fostering a climate of fearfulness. Another nuclear power plant accident that occurred in the past was introduced to the audience, but it differed in scale and could make public misunderstand. ${ }^{39}$

Friedman compared and contrasted the way of reporting the risk of radiation after three nuclear accidents: Three Mile Island, Chernobyl and Fukushima. ${ }^{40}$ One of the similarities of reporting three accidents was that journalists reported on-going incidents in real time even though it sometimes led to lack of accuracy. Because of the nature of a nuclear accident, how to deal with technical jargons was one of the challenges at press conferences and interviews. Most of the journalists were not so knowledgeable about radiation. The author points out that the variety of terminologies for the measurement of radiation was an element to make the risk communication between journalists and the public more complex. Another difficult part in communication was as to describing "potential health effects" (p57).

In Friedman's comparison of the media coverage of nuclear crisis cases, the case of Three Mile Island was that a lot of the media used X-ray radiation to explain row-dose radiation and the amount of the information was limited as discussed earlier in the present paper. In Chernobyl, the description of the extent of the scattering radiation was not numerical, and it covered just the levels of radiation. In Fukushima, long and detailed feature articles were published with info-graphics and multimedia outlets. Interaction of reporters and readers were very active in the case of Fukushima on the Internet.

The most notable difference among three accidents was that the case of Fukushima was the first nuclear accident after the age of the Internet, which changed how the information was provided via the Internet along with the traditional media such as TV and newspapers saying as follows:

- "The Internet, websites, and social media are major reasons for the deluge of Fukushima information, and they have changed the definition of mass media in many ways" (p56). ${ }^{40}$

- "Scientists offered extensive online tutorials about nuclear plants and radiation, and science journals such as Nature and Science posted articles on their news pages" (p56). ${ }^{40}$

- Many individuals and groups published online their updates and interpretations of news from traditional news or other web outlets such as websites, blogs and 
messages on SNS. Twitter discussions under many hash-tags such as \#Fukushima or \#nuclear. Other online tools including Wikipedia and Google search changed the way of receiving information although the author pointed out that lack of accuracy is problematic regarding the online information.

In this way, the case of Fukushima was illustrated as an improved media coverage compared to the past cases of Three Mile Island and Chernobyl media analysis point of view. The author generally described the tendency positively, however, more research should be necessary on how the audience perceived the information of radiation and how they selected the information during Fukushima disaster would be necessary.

\section{Risk communication and emotion}

A recent article suggested that the public and scientific community should discuss risk in the social context for the purpose not only of raising public familiarity with scientific knowledge or public engagement of activities related to science but also for considering how to live in a risky society with the support of such knowledge. ${ }^{41}$ The article also demonstrated the importance of developing public trust for providers of scientific information by addressing the emotional concerns of citizens, as opposed to making rational appeals.

In another research field, classical rhetoric, it has argued that Aristotle's three elements of persuasion - ethos (trust), logos (logical appeal), and pathos (emotional appeal) should be employed in good balance, in the society even related to science and technology (e.g., science policy). ${ }^{42}$ Too much logical approach without ethos and pathos could lead rushing to a conclusion because of the scientific community's prejudice against emotion during the policy-making process. It also explained that the denial of emotions could lead to logical leap, emotional manipulation, or lack of social morals. Thus, emotional aspect of communication is of importance in various discussions, not only in perception research or psychology research.

Moreover, in empirical studies of social science, the sub-rationality of collective actors in modern societies has been studied. As an emotional aspect, anger, is one of the keys to motivate individuals to participate in collective action for the change of the society especially in the situation of relative deprivation. ${ }^{43,44,45}$

\section{Parents' perception study after the Fukushima accident}

In the case of the Fukushima nuclear explosion, parents with small children were thought to be part of a social cluster that suffered the most from the disaster. According to the report from the Fukushima prefecture, more than 160,00o people who were forced to evacuate their homes in Fukushima remain displaced, and lots of parents and children are included. ${ }^{46}$

In this case of crisis, the public had strongly requested scientific information about low dose radiation before such information was released. They would have appreciated more immediate and detailed scientific information about the risks of low dose 
radiation so that they could consider prompt evacuation and food/water safety better. This was a different situation to other science communication topics to imply a "deficit model," or illustration of a scientific case study, offering scientific knowledge for enlightenment, education, and improved public engagement with the scientific community or science policy.

Many parents after the Fukushima nuclear disaster have felt uncomfortable with their families' living situations since the nuclear disaster. ${ }^{47}$ A key emotional element would be worry or anxiety in comparison with the case of collective actors' anger. We would like to see the relationship among the parents' anxiety, trust, and information for risk communication. The parents' psychological situation from the aspect of emotion (especially levels of anxiety) and distrust of information providers would necessary to be researched further so that this social issue has some resolutions; improved risk communications would undoubtedly help.

\section{Objectives}

To improve risk communications regarding low dose radiation, we developed the research questions below:

- What are the actual details regarding Japanese parents' anxiety levels and the underlying causes? How do differences in gender and distance from the exploded plant affect anxiety?

- How have the information sources in Japan influenced public perception of low dose radiation since the explosion and what are the key elements to building public trust and reducing public anxiety?

\section{Methods}

\section{Consideration of research methodology}

Perception survey was selected as our methodology by following other past studies from psychometric paradigm approach.

In the field of science communication, Gurabardhi described the development of methodologies to analyze risk communication with five main approaches such as psychometric paradigm, cultural risk theory, the mental models approach, the attitudebehavior models, and the stress-coping paradigm. ${ }^{48}$ These approaches are based on the risk assessment of the public's subjective features rather than objective risk measurement. Other review work done by Kallens et al. demonstrated empirical researches of perception and communication by searching reports on empirical research analysis on flood risks. ${ }^{49}$

The mainstream of risk perception research is psychometric paradigm introduced by Fischhoff et al. and Slovic. ${ }^{50,51}$ That aims to quantify each person's risk perception by conducting a survey with questionnaires. As most of the reviewed perception studies 
after nuclear accidents selected psychometric paradigm (Prince-Embury and Roony in Three Mile Island and Eiser in Chernobyl), we followed them by selecting psychometric paradigm for our research. ${ }^{14,15,17}$

\section{Survey}

Online survey was selected as it enabled us to reach the broader range of parents in Japan who have access to the Internet with bigger number of samples.

A survey on the Internet was selected as the research method while the perception survey conducted after nuclear accidents in the past were by mails or interviews. ${ }^{14,15,17}$ There have been discussions about the suitability of an Internet survey for academic research in the social sciences or science communication studies. An article pointed out that an Internet survey could have only limited functions as empirical research. However, a case study about genetically modified food was conducted with a survey distributed via the Internet and by post; Findings were not a largely different for contents of responses on computer-based questionnaires and paper questionnaires. Although there were differences demographically according to gender and distribution of generations, the contents of the answers between computer-based and paper-based did not change. But responses to computer-based questionnaires tended to be more extreme such as "strongly agree" or "strongly disagree.", 52

Although limited social clusters use the Internet and its use for survey purposes is unorthodox for sampling and answering questions, benefits of an Internet survey include its potential to reach a wider and larger sample and preserve the anonymity of respondents. Consequently, it was anticipated that more answers were honest.

After considering the merits and demerits of the Internet survey, we set our focus on parents in Japan with access to the Internet; survey questions were designed to assess the public's risk perceptions about low dose radiation and related information. Limiting the group to those with the Internet access solved the issues of the Internet survey.

\section{Samples}

Four regional groups of parents in Japan were selected for the online survey to investigate the differences of perception according to gender and distance/level of contamination in the environment.

The past similar researches focused on several groups for their studies: PrinceEmbury and Rooney interviewed two groups by face-to-face: residents who moved and those who remained after four years of TMI accident. ${ }^{14,15}$ Eiser et al conducted perception research in regards to four social clusters of three regional groups in Sweden according to the distance from the Chernobyl accident by a mail survey. ${ }^{17} \mathrm{We}$ also designed the survey to investigate the difference in gender and distance from the accident.

Japan has major district names from Northern regions to Southern regions as follows: Hokkaido, Tohoku, Kanto, Kansai, Chubu, Shikoku, Chugoku and Kyushu, etc. Among them, sample groups were selected by picking up three districts (Tohoku 
region, Kanto region, and Kansai region) along with Fukushima prefecture for the survey regarding differences in public perception of low dose radiation based on distances from the Fukushima Daiichi Nuclear Plant. Specific descriptions of the regions follow:

- Fukushima prefecture, in which the Fukushima Daiichi Nuclear Plant is located

- Tohoku region (within $300 \mathrm{~km}$ of the nuclear plant) next to the north side of the Fukushima prefecture; area damaged by Great East Japan Earthquake (Usually Japanese people call Tohoku including Fukushima prefecture, but this study Fukushima prefecture is excluded in Tohoku group and we made it as another group.)

- Kanto region (within $300 \mathrm{~km}$ of the nuclear plant) to the south of the Fukushima prefecture; includes the Tokyo metropolitan area

- Kansai region (outside the $300 \mathrm{~km}$ radius of the nuclear plant) including the area of Kyoto City

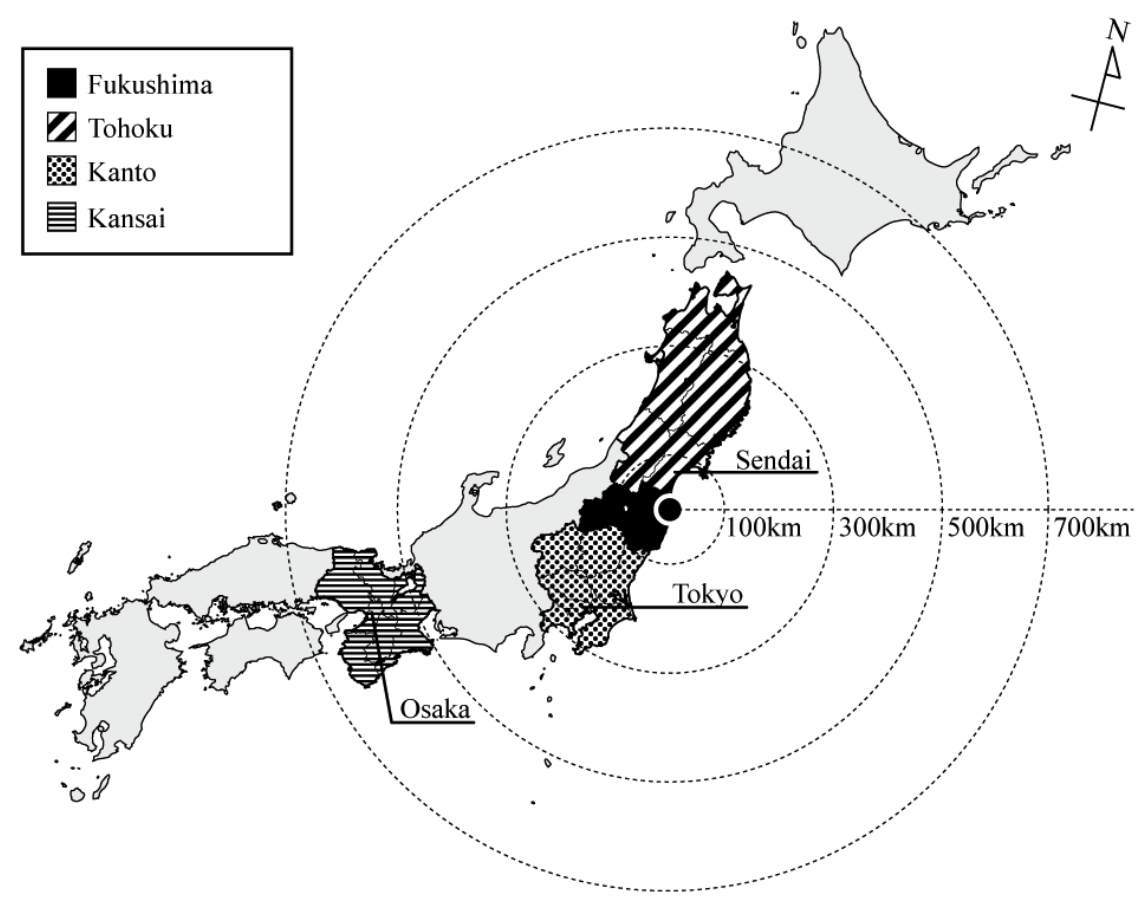

Figure 1. Four regional groups for online survey: Fukushima, Tohoku, Kanto and Kansai. A black dot in the center of the map is the place of Fukushima Daiichi Nuclear Plant.

Figure 1 shows the areas of each group. The levels of contamination from radiation in regards to the air and soil were different in the four regions. Some areas in Fukushima prefecture had the most severe contamination, the areas in Tohoku region and Kansai tended to show less severe contamination, and the furthest areas in Kanto tended to show much less contamination. We intended to look at co-relation between the perception, gender and distance/level of contamination after the Fukushima accident. 
In our survey, the data was gathered by NTT Resonant, Inc., a research and marketing company. The survey was conducted March 12-15, 2012, about one year after the Great East Japan Earthquake (March 11, 2011) followed by the Fukushima nuclear disaster. In total, the company collected responses from 1,793 parents living in Japan.

The timing of the survey, one year after the accident, was selected as the following reasons: 1) If it was earlier, the respondents would not have been ready for the survey because of the time and physical constraints such as evacuation and recovery of their lives from the disaster. 2) If conducted later, the tendencies of their perception affected by the accident would have disappeared.

We chose NTT Resonant, Inc., for its website called "goo" (http://www.goo.ne.jp/), an online platform for news and searching functions (similar to Yahoo! and Google). The company conducted a survey for users with free goo accounts. Anyone with access to the Internet can create free accounts. By soliciting survey respondents from account holders, the methodology was similar to random sampling.

\section{Questionnaire}

Four questions to select and two open-ended questions were asked in questionnaire. It aimed to take merit and demerit both of questions to select and open-ended questions.

Discussions have taken place regarding the ideal way to ask questions to obtain realistic perceptions regarding scientific issue. An article introduced the "open-ended question," in which respondents were asked to reply to survey questions in the survey by writing text in their own words. The merits of the open-ended question are the variety of response data and realistic descriptions illustrating current societal issues. ${ }^{53}$

In the questionnaire, six questions investigated the parents' perceptions regarding low dose radiation: extent of anxiety, reasons for anxiety, trusted people, trustworthy media, interesting news topics about low dose radiation, and requests to information providers. Participants could respond with a single answer, multi answers, or free text in response to an open-ended question. The rates of anxiety in our questionnaire were close to the ones by Prince-Embury and Rooney after TMI; 1=not at all worried, $4=$ very worried. ${ }^{14,15}$

\section{Analysis}

Selected answers were analyzed as quantitative data and text answers were analyzed as qualitative data. With the combination of these two kinds of data, we looked at overall tendencies of the survey.

The parents' answers collected by NTT Resonant, Inc. were analyzed; text answers in the last part of the questionnaire were examined by the procedure of text analysis, consulting literature of discourse analysis. ${ }^{54}$ In some researches, data was analyzed statistically with software designed for psychological and sociological analysis, such as SPSS. ${ }^{55}$ In this survey, we chose certain answers to analyze statistically; we conducted text analysis of the written answers for two open-ended questions. Text analysis included reading each written text and categorizing similar answers into a top 10 list. 


\section{Results}

\section{Respondents}

The total number of respondents was 1,793. All responses were valid for statistical analysis. Age distribution of respondents included $62.4 \%$ in their $30 \mathrm{~s}, 25 \%$ in their $40 \mathrm{~s}$, $12.2 \%$ in their $20 \mathrm{~s}, 1.3 \%$ in their $50 \mathrm{~s}$, and $0.1 \%$ in their $60 \mathrm{~s}$. Regarding gender, $40 \%$ (718 people) of parents surveyed were fathers and 60\% (1075 people) were mothers. Regarding respondents' children, more than a half of the respondents had small children under seven years old.

The distribution of the respondents by region was as follows: $4.1 \%$ (74 people) in the Fukushima prefecture, 28.1\% (55 people) in the Tohoku region, 47.6\% (853 people) in the Kanto region, and $24.3 \%$ (435 people) in the Kansai region. Regarding occupations of the respondents, $41.4 \%$ were housewives or househusbands; $14.2 \%$ were engineers or professionals with expertise and $10.7 \%$ were administrators.

\section{Levels of anxiety based on location and gender}

A total of $73.3 \%$ of the Japanese parents surveyed experienced anxiety after the Fukushima explosion. By region, 52.7\% of parents in the Fukushima prefecture experienced "strong anxiety" that was higher than in other regions. There were no differences between the Tohoku and Kanto regions as shown figure 2. Further out in the Kansai region, the data shows a low percentage of responses for "strong anxiety." The comparison between fathers and mothers in the Fukushima prefecture revealed the notable differences, indicating that $64.6 \%$ of mothers and $30.8 \%$ of fathers experienced "strong anxiety." Overall, parents in Fukushima 74.9\% of fathers and $72.8 \%$ of mothers experienced some level of anxiety after the nuclear disaster. In the three other regions, there was no such difference in the selections of "strong anxiety" or "anxiety" by fathers and mothers (figure 3 ).

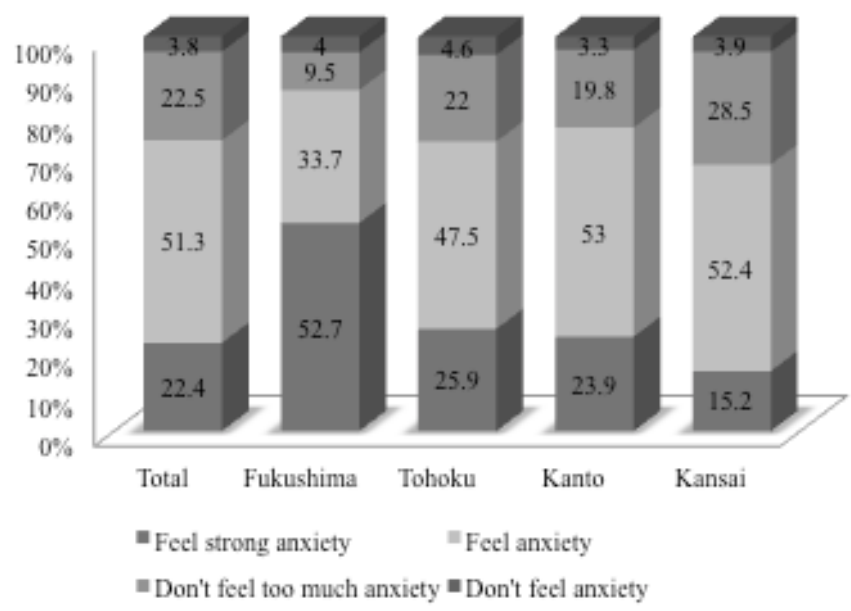

Figure 2. Comparison of anxiety levels according to region. 


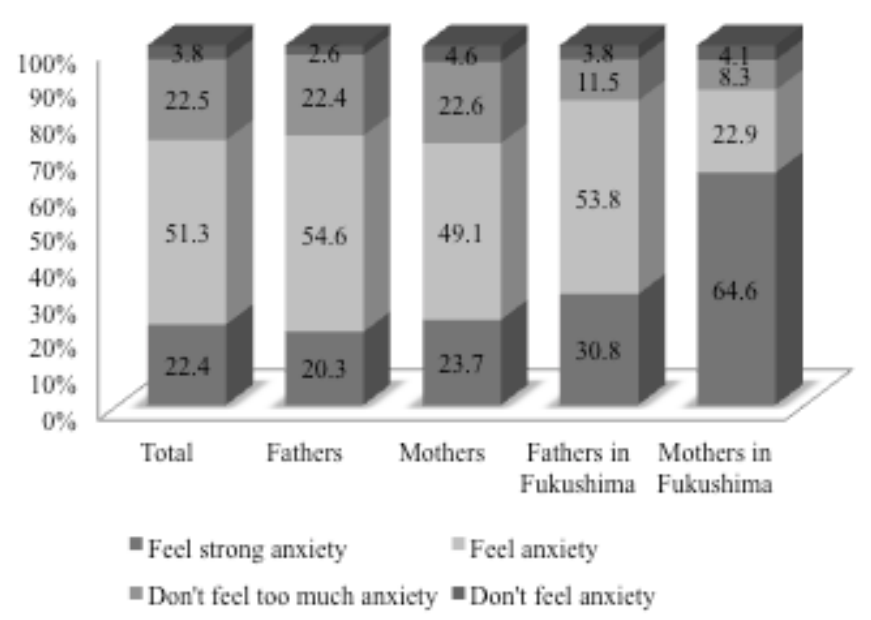

Figure 3. Comparison of anxiety levels by gender.

\section{Reasons for feelings of anxiety according to locations}

Based on the offering of multiple answers for each question, the predominant reason for feelings of anxiety was distrust of the government's position (table 1). The second reason was uncertainty about scientific data disseminated in the past about low dose radiation and its invisible risks, such as hot spots (a small spot with high dose radioactive materials) and food that had not been monitored carefully for radiation. "Lack of scientific knowledge regarding low dose radiation" was selected less frequently than expected. According to region, more respondents in the Fukushima prefecture expressed "uncertainty of low dose radiation," while respondents who lived further away from the nuclear plant tended to experience "ambiguous anxiety" as shown in table 1. 


\begin{tabular}{|c|c|c|c|c|c|c|c|c|}
\hline & & Total & $\begin{array}{l}\text { Uncertainty } \\
\text { of low dose } \\
\text { radiation }\end{array}$ & $\begin{array}{l}\text { Lack of } \\
\text { knowledge } \\
\text { regarding } \\
\text { low dose } \\
\text { radiation }\end{array}$ & $\begin{array}{l}\text { Distrust of } \\
\text { the outlook } \\
\text { and actions } \\
\text { by the } \\
\text { government }\end{array}$ & $\begin{array}{l}\text { Hotspots and } \\
\text { unintentional } \\
\text { intake of } \\
\text { contaminated } \\
\text { food }\end{array}$ & $\begin{array}{c}\text { Ambiguous } \\
\text { anxiety } \\
\text { without } \\
\text { any } \\
\text { reasons }\end{array}$ & $\begin{array}{l}\text { Other } \\
\text { reasons }\end{array}$ \\
\hline \multirow[t]{2}{*}{ Total } & $\%$ & 100 & 40.7 & 29.2 & 45.2 & 40.8 & 8 & 1.7 \\
\hline & Number & 1793 & 730 & 523 & 811 & 732 & 143 & 30 \\
\hline \multirow[t]{2}{*}{$\begin{array}{l}\text { Fukushima } \\
\text { prefecture }\end{array}$} & $\%$ & 100 & 73 & 36.5 & 62.2 & 52.7 & 2.7 & 1.4 \\
\hline & Number & 74 & 54 & 27 & 46 & 39 & 2 & 1 \\
\hline $\begin{array}{l}\text { Tohoku } \\
\text { region }\end{array}$ & $\%$ & 100 & 41.8 & 30.6 & 43.9 & 40.6 & 6.7 & 1.9 \\
\hline $\begin{array}{l}\text { (Excluding } \\
\text { Fukushima) }\end{array}$ & Number & 431 & 180 & 132 & 189 & 175 & 29 & 8 \\
\hline \multirow[t]{2}{*}{$\begin{array}{l}\text { Kanto } \\
\text { region }\end{array}$} & $\%$ & 100 & 41.6 & 28.4 & 49 & 45 & 6.8 & 2.1 \\
\hline & Number & 853 & 355 & 242 & 418 & 384 & 58 & 18 \\
\hline \multirow[t]{2}{*}{$\begin{array}{l}\text { Kansai } \\
\text { region }\end{array}$} & $\%$ & 100 & 32.4 & 28 & 36.3 & 30.8 & 12.4 & 0.7 \\
\hline & Number & 435 & 141 & 122 & 158 & 134 & 54 & 3 \\
\hline
\end{tabular}

Table 1. Residential differences and reasons of anxiety regarding low dose radiation.

\section{Whose advice to trust}

Also by offering the multiple answers, the people whom the respondents trusted the most after the Fukushima nuclear disaster explosion were academic scholars $(40.2 \%$, 720 responses). The second most trusted people were family members and relatives $(32.9 \%, 590)$, followed by medical doctors $(28.6 \%, 512)$. Once scholars spoke out frequently in the media, they became less trusted $(28.6 \%, 512)$ by the respondents. Other people identified in the questionnaire were journalists $(21.4 \%, 383)$, friends $(13.7 \%, 245)$, teachers at school $(11.1 \%, 199)$, and others $(15.2 \%, 272)$.

\section{Trustworthy media after the explosion}

In terms of trust for the media after the Fukushima nuclear plant explosion, traditional news media rewarded with public trust included Japan Broadcasting Company (a national broadcast company), print newspapers, and other commercial TV broadcasting 
companies (figure 4). The respondents selected academia as the next most trusted source for information; they cited websites of academic institutes and scholarly publications, although the general public accesses them less frequently. Parents as respondents did not trust social networking services as much as we would have expected.

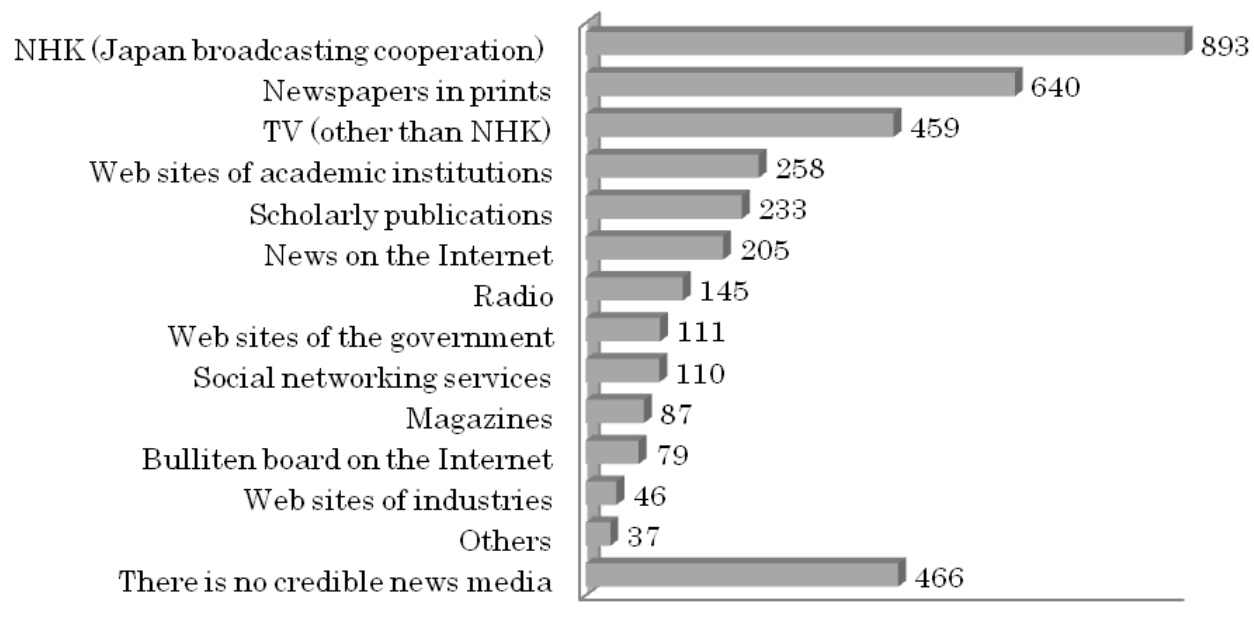

$0 \quad 100200300400500 \quad 600700800900$

Figure 3. Trusted media.

\section{Food and health effects were the parents' most interested news topics}

Text answers regarding the most interesting news topics about low dose radiation and childcare were categorized. The news topics that Japanese parents (128 people) found the most interesting were something related to food safety; examples included information about the new food monitoring system that began one month after the survey, contamination of fish and milk, and consequences of unintentional intake of contaminated food. The next topic of interest for 113 respondents was the possible health effects on children over a long-term period; since this topic concerned caring for the next generation, parents expressed vague anxiety. The third topic of interest for 104 respondents was news related to evacuation. Some families with small children left the Fukushima prefecture because of radiation's possible health effects on their children; after evacuating, many families found it difficult to settle down again. Fourth, 102 respondents expressed concern about the current status of their children's health (e.g., thyroid gland and radioactive cesium in urine). Fifth, parents wanted exact data about safety of playgrounds and cleaning activities for the removal of radioactive materials. Although there were many reports in the Japanese media about the Chernobyl accident to explain what was happening in the Fukushima accident, only 39 respondents wrote that they were interested in the information related to Chernobyl. A total of 524 survey participants selected "No response" and "I don't know" for the question related to new topics of interest. 


\section{Request to information providers}

In the text answers citing requests to information providers, the topic most frequently referred to concerned needed improvement in the quality of information about low dose radiation (table 2). Respondents complained of unclear or incorrect statements, presentations that stirred up negative emotions, delays in release of information, lack of objectivity, and unimportant information.

Another topic frequently cited in text answers was a request for greater specificity in disseminated information. Regarding the risks of low dose radiation and preventive measures for children, the respondents wanted concrete recommendations about protective measures rather than mere explanations of the scientific mechanism of radiation. For example, they requested more information on food safety and radiation data of local residences, indicating their interest in the daily influence of potential radiation exposure.

\begin{tabular}{|lr|}
\hline Requests to information providers & Comments \\
\hline Improvement in the quality of information & 164 \\
\hline More specific information about the risks of radiation & 92 \\
\hline Concrete recommendations for protection from radiation effects & 60 \\
\hline Guidance regarding how to access the first scientific source & 59 \\
\hline More information about food safety & 59 \\
\hline Data of radioactive materials in local residences & 50 \\
\hline Improvement in dissemination of important information from the & \\
government & 39 \\
\hline More direct information from the first scientific source & 25 \\
\hline More information about other risks associated with daily life & 20 \\
\hline More data and information from abroad & 17 \\
\hline More TV programs on low dose radiation & 17 \\
\hline More positive information & 17 \\
\hline Others & 119 \\
\hline No answers & 1055 \\
\hline Total & 1793 \\
\hline
\end{tabular}

Table 2. Requests to information providers.

In summary,

1. In the Fukushima region, mothers (64.4\%) expressed much stronger anxiety than fathers $(30.8 \%)$ whereas other regional groups did not show such tendency.

2. Many respondents did not attribute their anxiety to a lack of knowledge about low dose radiation; instead, they attributed it to their distrust of the government and the uncertain effects of low dose radiation.

3. The most trusted people after the explosion were scientists, followed by family members and relatives. Regarding information sources, Japan Broadcasting Company and print newspapers had high credibility.

4. The strongest requests to information providers were to improve the quality of information, avoid stirring up negative emotions, and disclose full information. 


\section{Conclusion}

\section{How to deal with mothers' strong anxiety in Fukushima}

We investigated Japanese parents' perceptions about the risks of low dose radiation after the Fukushima nuclear accident. Looking at the first result summarized above regarding the extent of anxiety, more than $70 \%$ of respondents expressed "feeling anxiety" ("strong anxiety" or "anxiety"), which is an unusual rate. The perception research done after the Chernobyl accident described that farmers and parents had expressed strong psychological reactions to the nuclear accident. ${ }^{17}$ In our perception study, although we did not investigate other social clusters' perceptions for comparison or as control, the results confirmed the strong anxiety levels of parents in the case of Fukushima. In this survey, residential distance from the nuclear plant and gender were effective variables to clarify the tendencies of parents' anxiety after the Fukushima nuclear accident.

The most notable result was that mothers in the Fukushima prefecture expressed much stronger anxiety than fathers. A past report after the Chernobyl accident indicated that men and women tended to perceive risks of radiation differently. ${ }^{18}$ Such tendency would grow among parents living near a nuclear accident as our data showed. Fathers and mothers felt similar levels of anxiety in other regional groups.

The Fukushima accident happened after 25 years of the Chernobyl accident. In the age of the Internet, scientific information providers have varieties of contents and tools to tell the audience as Friedman pointed out, which made the information more available and accessible. ${ }^{40}$ However, the fact did not directly lead the audience to receive satisfactory information, which still made the parents after the Fukushima accident felt strong anxiety.

Discussions of public perception and risk communication research after Three Mile Island and Chernobyl as follows could be some clues to improve the situation of parents in Fukushima, too:

1) Information should be supporting parents, especially mothers, in order to have higher levels of perceived control in regards to their lives after the accident. ${ }^{13-15}$

2) Information should be easing parents' (especially mothers') too much feeling of responsibility to the risk management of their children after the accident such as by the risk of food contamination. ${ }^{17}$

Our data of text answers to the survey also showed that the risks related to food were of great concern to the parents. The goal and motivation of providing information after a nuclear accident should be set with consideration of above discussions. For example, news coverage in regards to parents' anxiety of low dose radiation tended to include the interviews only of mothers with small children, and it could lead misunderstanding that only mothers take responsibility in the issue; the interviews of fathers and other local community members talking about risk management for children's health would improve the perception of the audience including the mothers. 


\section{Regional differences of the most critical information after the accident}

Moreover, even in the same country, there were remarkable differences in parents' anxiety levels toward low dose radiation based on distance from the Fukushima nuclear plant. The selected reasons of their anxiety also varied; the parents living in a region close to the explosion also tended to think more realistically about the government's response and scientific facts regarding the explosion than those in further regions who experienced ambiguous anxiety.

The results indicate the difference of the most critical topic of the information after the nuclear accident in regions; for example, in Fukushima prefecture, the most important one would have been at first how to decide evacuating or not whereas in much further place like Kanto, how to cope with the stress of ambiguous anxiety would matter. Appropriate actions and dissemination of necessary scientific information should vary, therefore, in accordance with proximity of a residence to the plant. This conclusion is consistent to the research by Drottz and Sjoberg, the successful element of risk communication is to influence the risk attitudes of the targeted audience by providing critical information because each group has different motivation to gain the information. ${ }^{56}$

Other recent researches conducted in Japan have pointed out that, by analyzing news articles and communications among social networking services, mass media after 3.11 followed by Fukushima nuclear disaster had tended to report a lot of news to the majority of the audiences living in Tokyo metropolitan areas rather than to the individuals in the regions heavily damaged by the earthquake, tsunami or the Fukushima nuclear explosion although, for the latter people, information would have been even more indispensable to recover from the catastrophic event. ${ }^{57,58}$ The regional differences of the most critical information should be more considered in risk communication after a nuclear accident.

\section{Information to support personal decision-making after the accident}

The second result summarized above shows that communicating scientific information about low dose radiation does not necessarily mean the explanation for the purpose of fulfillment of scientific learning. The parents responded that their feelings of anxiety toward radiation were caused by "discontent about the government's leadership and release of information," as well as "scientific uncertainties about low dose radiation" and "the ambiguous effects of low dose radiation to the environment." Contrary to our estimations, only a limited number of respondents selected "lack of scientific knowledge" as a reason for feeling anxious.

Generally, the purposes of communication after the nuclear accident still tended to be interpreted as delivering complex scientific contents in a way that the public can understand in Japan, which would have been categorized as "deficit model." Rather, the parents who responded wanted specific recommendations based on discussions between experts, governmental agencies, and mediators for the individual decisionmaking process regarding topics related to their daily lives. For example, day-to-day 
risk management topics such as food, water, local environment and evacuation should be included in the priority list to cover. As previously discussed, such information of topics should be ideally provided in accordance with the regional differences of priorities.

As Renn discussed, the important topics of the audience after a nuclear accident are how to cope with and how to manage the risk and hazard, rather than the technical explanation of nuclear explosion itself. ${ }^{20}$ Our results of parents' perception after the Fukushima case confirmed the point again, and it implied the challenge of practices for the mediators to demonstrate how to cope with and manage the risk and hazard after a nuclear accident so that the audience are supported to make a individual decisionmaking with satisfaction.

\section{Risk communication after a nuclear disaster in the age of the Internet}

Such kinds of engagement by mediators would be successful in combination of the traditional media and other media on the Internet. According to the third result noted above, respondents selected traditional media including NHK (i.e., Japan Broadcasting Corporation) and print newspapers as more trustworthy than social networks such as Twitter and Facebook for communicating and sharing information during and after such crises as 3.11 and the Fukushima Daiichi nuclear plant explosion.

There were some helpful information accessible to the Internet, but evaluation of trustworthiness and scientific soundness in regards to the information was more difficult than usual after the accident since more rumor and false information frightened the audience. In terms of the fourth result summarized above regarding Japanese parents' requests to scientific information providers (i.e, media, public relations firms, publishers, and communicators), there were numerous recommendations for improved communication about the effects of low dose radiation. Improving the quality of scientific communications in society was the top priority based on reports that some articles in the media had stirred up negative emotions or sent inappropriate and incorrect information.

Our results of the survey only showed the tendency of parents, not other social clusters, and another research should focus on discussing further how the Japanese traditional media should have worked after the Fukushima accident. Here, it should be stressed that both of the media could work complementary for making use of the higher credibility of traditional media and the promptness of participatory other media on the Internet. As Lemyre et al said: "Social media applications present new methods of delivering messages to the public. By using these new conduits for information dissemination, it becomes possible to reach a larger number of people in a timely manner with preventive and mitigating recommendations. Supplying pro-social images of successful and innovative coping strategies and reminding the media of constructive advice can support them in playing their role of assistance to the public"(p20). ${ }^{23}$

We perceived the need for mediators to engage in communication at a more personal level. For example, 14 survey respondents in their text answers requested "a single trustworthy web site for parents" with scientific information related to parenting. Six 
respondents stated that schools should play greater roles in distributing information about low dose radiation as part of "science education."

Additionally, websites of academic institutes and academic publications were selected as rather trustworthy, but they were not so accessible to the public. In other words, lack of publicity kept them off the top of search engine lists or access was limited for paid journal articles. After the explosion, both sources could have been important in risk communications.

In conclusion, the audience's individual decision-making process would be supported by the information of different day-to-day risk management topics such as food, water, environment and evacuation in accordance with the targeted audience. Improving the perception of local residents near the nuclear accident by raising the levels of perceived control and easing the tension of too much responsibility to others' lives would be keys to discuss further. Slovic stressed, after Chernobyl, a strong necessity to be better prepared for risk communication of a nuclear accident. ${ }^{12}$ After Three Mile Island, Chernobyl, and then Fukushima, we restate this statement of urgent preparedness.

\section{Notes and references}

${ }^{1}$ Report of meeting on how to construct the safe and relievable society with science policy (in Japanese), http://www.mext.go.jp/a menu/kagaku/anzen/houkoku/04042302.htm, accessed on December 26, 2012

2 What is SPEEDI (in Japanese), http://www.bousai.ne.jp/vis/torikumi/030101.html, accessed on December 26, 2012.

${ }^{3}$ Press Conference on March 19, 2011, by the Chief Cabinet Secretary on The levels of radiation in spinach and milk raised close to Fukushima Daiichi Nuclear Plant (in Japanese), http://www.kantei.go.jp/jp/tyoukanpress/201103/19_p.html, accessed on January 9, 2013.

4 Symposium archive of Japanese Association of Science and Technology Journalists on Reporting Fukushima accident, held on November 6, 2011 (in Japanese) http://aichi-science.jp/events/single/46, accessed on January 22, 2013.

5 A. Suzuki and S. Kimura (April 2, 2011), Self-restraint of publishing prediction of spreading radioactive fallouts (in Japanese), Asahi Shimbun,

http://www.asahi.com/special/10005/TKY201104020166.html, accessed on December 26, 2012.

6 K. Nakagawa et al.(April 2012), How books of nuclear accident were read (in Japanese), Chuou Kouron.

${ }^{7}$ Fukushima Prefecture Homepage (in Japanese), http://wwwcms.pref.fukushima.jp/pcp portal/PortalServlet;jsessionid=9216F185DBF36534440CF101294B3BBA ?DISPLAY ID=DIRECT\&NEXT DISPLAY ID $=U 000004 \& C O N T E N T S ~ I D=26411$, accecced on December 26,2012

${ }^{8}$ Data of food monitoring about radioactive materials (in Japanese), http://www.mhlw.go.jp/stf/houdou/2r9852000002rtdl.html, accessed on December 26, 2012

9 Survey on the trust of mass media after the Great East Japan Earthquake (in Japanese), http://www.nri.co.jp/news/2011/110329.html, accessed on December 26, 2012.

${ }^{10}$ T.C. Earle and G. Cvetkovich (1990), What was the meaning of Chernobyl?, J. Environ. Psychol. 10: 169-176.

${ }^{11}$ S. Weart (1988), Nuclear Fear, Harvard University Press, Cambridge, MA, U.S.A.

${ }^{12}$ P. Slovic (1996), Perception of Risk from Radiation, Radiat. Prot. Dosimetr 68 (3/4): 165-180.

${ }^{13}$ E. Langer (1983), The psychology of control, Sage Publications, Beverly Hills, CA, U.S.A.

${ }^{14} \mathrm{R}$. Prince-Embury and J.F. Rooney (1989), A comparison of residents who moved versus those who remained prior to restart of Three Mile Island, J. Appl. Soc. Psychol. 19 (11): 959-975.

${ }^{15}$ S. Prince-Embury and J.F. Rooney (1978), Perception of control and faith in experts among residents in the vicinity of Three Mile Island, J. Appl. Soc. Psychol. 17 (11): 953-968.

${ }^{16}$ A. Baum, R. Gatchel, and M. Schaeffer (1983), Emotion, behavioral and physiological effects of chronic stress at Three Mile Island, J. Consul. Clin. Psychol. 51(4): 656-672. 
${ }^{17}$ J.R. Eiser, B. Hannover, L. Mann, M. Morin, J. Van der Pligt and P. Webley (1990), Nuclear attitudes after Chernobyl: a cross-national study, J. Environ. Psychol. 10: 101-110.

${ }^{18}$ B. Hoijer (1987), Information gain, assessment of risks and behavior related to the nuclear power accident at Chernobyl and its consequences in Sweden, Sveriges Radio, Stockholm, Sweden, unpublished manuscript.

${ }^{19}$ H.P. Peters (1992), The credibility of information sources in West Germany after the Chernobyl disaster, Publ. Understand. Sci. 1:325-343.

${ }^{20}$ O. Renn (1990), Public responses to the Chernobyl accident, J. Environ. Psychol. 10: 151-167.

${ }^{21}$ F.N. Hippel (2011), The radiological and psychological consequences of the Fukushima Daiichi accident, B. Atom. Sci. 67(5): 27-36.

${ }^{22}$ Chernobyl Forum (2006), Chernobyl's Legacy: Health, Environmental and Socio-Economic Impacts and Recommendations to the Governments of Belarus, the Russian Federation and Ukraine, 2nd revised version, http://www.iaea.org/Publications/Booklets/Chernobyl/chernobyl.pdf.

${ }^{23}$ L. Lemyre et al. (2010), Psychosocial considerations for mass decontamination, Radiat. Prot. Dosimetr. 142(1): $17-23$.

${ }^{24}$ W. Leiss (1996), Three phases in the evolution of risk communication practice, Ann. Am. Acad. Polit. Soc. Sci. 545:85-94.

${ }^{25}$ A. Boholm (2008), New perspectives on risk communication: Uncertainty in a complex society, J. Risk Research 11(1-2):1-3.

${ }^{26}$ L. Trettin and C. Musham (2000), Is trust a realistic goal of environmental risk communication?, Environ. Behav. 32(3):410-426.

${ }^{27}$ M.G. Mogan et al. (2001), Risk Communication: a mental models approach, Cambridge, U.K.

${ }^{28}$ L. Sjoberg (2007), Emotions and risk perception, Risk Management 9: 223-237.

${ }^{29}$ V.H.M. Visshchers and M. Siegrist (2008), Exploring the triangular relationship between trust, affect and risk perception: a review of literature, Risk Management 10:156-167.

${ }^{30}$ K. Nakayachi (2011), Relationship between trust and anxiety toward managing risk, Shinrigaku Kenkyu (in Japanese) 82:467-472.

${ }^{31}$ R. Holt (1983), Human stress at TMI and other reactor regions, paper presented at Three Mile Island Public Health Fund Forum, Penn State/Capitol Campus.

${ }^{32}$ B. Dohrenwend, B. Dohrenwend, S. Kasl and G. Wowheit (1979), Report of the task force on behavioral effects of the President's Commission on the Accident at Three Mile Island, U.S. Government Printing Office, Washington, DC, U.S.A.

${ }^{33}$ B. Wynne (1992), Misunderstood misunderstanding: social identities and public uptake of science, Pub. Understand. Sci. 1: 281-304.

${ }^{34} \mathrm{R}$. Paine (1992), "Chernobyl" reaches Norway: the accident, science, and the threat to cultural knowledge, Pub. Understand. Sci. 1: 261-280.

${ }^{35} \mathrm{~K}$. Bultitude, P. Rodari, and E. Weitkamp (2012), Bridging the gap between science and policy: the importance of mutual respect, trust and the role of mediators, JCOM 11(03): C01.

${ }^{36}$ A. Mazur and J. Lee (1993), Sounding the global alarm: environmental issues in the US national news, Soc. Stud. Sci. 23: $681-720$.

${ }^{37}$ J.L. Durfee (2006), "Social Change" and "Status Quo" Framing Effects on Risk Perception, Sci. Commun. 27: 259.

${ }^{38}$ A.A. Wahlberg (2000), Risk perception and the media, J. Risk Research 3(1): 31-50.

${ }^{39}$ S.M. Friedman, C.M. Gorney and B.P. Egolf (1992), Chernobyl coverage: how the media treated the nuclear industry, Pub. Understand. Sci. 1: 305-323.

${ }^{40}$ S.M. Friedman (2011), Three Mile Island, Chernobyl. And Fukushima: An analysis of traditional and new media coverage of nuclear accidents and radiation, B. Atom. Sci. 67(5): 55-65.

${ }^{41}$ E. Engdahl and R. Lidskog (2012), Risk, communication and trust: Towards an emotional understanding of trust, Pub. Understand. Sci., published before print on October 19, http://dx.doi.org/10.1177/0963662512460953.

${ }^{42} \mathrm{C}$. Waddell (1990), The role of pathos in the decision-making process: a study in the rhetoric of science policy, $Q$. J. Speech 76: 381-400.

${ }^{43}$ I. Walker and H.J. Smith (2002), Relative deprivation: Specification, development, and integration, Cambridge University Press, Cambridge, U.K.

${ }^{44} \mathrm{M}$. Van Zomeren et al. (2008), Toward an integrative social identity model of collective action: A quantitative research synthesis of three socio-psychological perspectives, Psychol. Bull. 134: 504-535.

${ }^{45} \mathrm{C} . \mathrm{W}$. Leach et al. (2006), Anger and guilt about ingroup advantage explain the willingness for political action, Pers. Soc. Psychol. B. 32: 1232-1245. 
${ }^{46}$ Fukushima Prefecture Homepage to support refugees (in Japanese), http://wwwcms.pref.fukushima.jp/pcp portal/PortalServlet?DISPLAY ID=DIRECT\&NEXT DISPLAY ID=U00 0004\&CONTENTS ID=28571, accessed on December 26, 2012.

${ }^{47}$ A. Takeshita. (July 6,2012 ), Fukushima's challenge to construct a system of releasing anxiety regarding low dose radiation (in Japanese), Nikkei Shimbun. http://www.nikkei.com/article/DGXDZO43414360V00C12A7EL1P01/, accessed on January 23, 2013.

${ }^{48}$ Z. Gurabardhi et al. (2004), The Development of Risk Communication An Empirical Analysis of the Literature in the Field, Sci. Commun. 25: 323.

${ }^{49}$ W. Kellens et al. (2013), Perception and communication of flood risks: a systematic review of empirical research, Risk Analysis 33 (1):24-49.

${ }^{50}$ B. Fischhoff, P. Slovic, S. Lichtenstein, S. Read and B. Combs (1978), How safe is safe enough? A psychometric study of attitudes towards technological risks and benefits, Policy Sci. 9: 127-152.

${ }^{51}$ P. Slovic (1987), Perception of Risk, Science 236(4799): 280-285.

${ }^{52} \mathrm{G}$. Rowe et al. (2006), A comparison of responses to Internet and postal surveys in a public engagement context, Sci. Commu. 27(3): 352-375.

${ }^{53}$ P. Stonemen et al. (2012), Exploring public discourses about emerging technologies through statistical clustering of open-ended survey questions, Pub. Understand. Sci., published before print on http://dx.doi.org/10.1177/0963662512441569.

${ }^{54}$ B. Johnstone. (2008), Discourse Analysis, Blackwell Publishing, Malden.

${ }^{55}$ D. Evensen and C.E. Clarke (2012), Efficacy information in Media Coverage of Infectious Disease Risks, Sci Comm. 34(3): 392-418.

${ }^{56}$ B-M. Drottz-Sjoberg L. and Sjoberg (1990), Risk perception and worries after the Chernobyl accident, J. Environ. Psychol. 10: 135-149.

${ }^{57}$ M. Tanaka et al. (2012), Minority in disaster and minority of receiving risk information (in Japanese), Chikuma Shobo, Tokyo, Japan.

${ }^{58}$ A. Takano et al. (2012), 3.11 information science (in Japanese), Iwanami Shoten, Tokyo, Japan.

\section{Authors}

Dr. Hiromi M. Yokoyama is an Associate Professor at the University of Tokyo, School of Science. She received her Ph.D. for her research on particle physics at the Tokyo University of Science, Tokyo, Japan. Her current research interest is science communication and science policy. Email: yokoyama@sp.s.u-tokyo.ac.jp

Saho Tateno is a Research Fellow at the University of Tokyo, School of Science. She received her M.A. in Written Communication at Eastern Michigan University, Ypsilanti, Michigan, the U.S.A., and M.S. in Life Science at Tohoku University, Sendai, Japan. Along with her research on science media and writing, she is also working as a freelance writer specialized in science and technology.

Email: tateno@sp.s.s.u-tokyo.ac.jp

How TO CITE: S. Tateno and H.M. Yokoyama, Public anxiety, trust, and the role of mediators in communicating risk of exposure to low dose radiation after the Fukushima Daiichi Nuclear Plant explosion, JCOM 12(02) (2013) A03. 